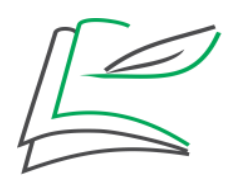

Entretextos

Entretextos 21(1): jan./jun. 2021

ISSN 1519-5392 UEL

DOI: $10.5433 / 1519-5392.2021 v 21$ n1.p.177

\title{
Traços de abordagens no ensino-aprendizagem de Português como Língua Estrangeira: uma experiência com professores em formação ${ }^{1}$
}

\author{
Traces of approaches in the teaching-learning of Portuguese as a \\ Foreign language: an experience with pre-service teachers
}

\begin{abstract}
Rasgos de abordajes en la enseñanza-aprendizaje de Portugués como Lengua Extranjera: una experiencia con docentes en formación
\end{abstract}

\author{
Renata Tironi de Camargo* \\ https://orcid.org/0000-0002-5303-834X \\ Tábata Quintana Yonaha* (Dhttps://orcid.org/0000-0002-8288-8351
}

\begin{abstract}
RESUMO: À luz de Almeida Filho (1997), Anthony (1963), Prabhu (1990) e outros, concebemos "abordagem" como a filosofia com potencial para orientar os processos de ensinar e de aprender de seus agentes. Neste trabalho, buscamos analisar elementos que possam indicar a predominância de abordagens no processo de ensino de PLE, por meio de concepç̃̃es acerca do ensino de língua apontadas por professores em formação, bem como da atuação desses agentes em projeto de extensão de uma universidade pública do interior paulista. Tendo isso em vista, apoiadas no paradigma qualitativo-interpretativista, utilizamos como instrumentos de produção de dados questionário semiestruturado, observação de aula, notas de campo e gravação de aula em áudio. A partir desses procedimentos metodológicos, identificamos que os professores em formação mobilizaram recursos pedagógicos alinhados à abordagem Gramatical Comunicativizada, já que fazem uso de práticas reconhecidamente estruturais, porém de forma contextualizada e justificada. Por fim, compreendemos que o reconhecimento de determinada abordagem pode ajudar a esclarecer práticas de professores e, oportunamente, auxiliar na reflexão dessas ações em busca do aprimoramento da ação profissional.
\end{abstract}

PALAVRAS-CHAVE: Português como Língua Estrangeira. Análise de abordagem. Professores em formação.

ABSTRACT: In the perspective of Almeida Filho (1997), Anthony (1963), Prabhu (1990) and others, we conceive an "approach" as a philosophy with the potential to guide the teaching and learning processes of its agents. In this work, we seek to analyze elements that may indicate the predominance of approaches in the teaching process of PFL, through conceptions over language teaching pointed out by pre-service teachers, as well as the performance of these agents in a project from a public university located in the state of São Paulo. This way, supported by the qualitative-interpretative paradigm, we carried out semi-structured questionnaires, class

\footnotetext{
${ }^{1}$ O presente trabalho foi realizado com apoio da Coordenação de Aperfeiçoamento de Pessoal de Nível Superior - Brasil (CAPES) - Código de Financiamento 001.

* Doutoranda em Linguística pela Universidade Federal de São Carlos. E-mail: renatatironi@hotmail.com

* Doutoranda em Linguística pela Universidade Federal de São Carlos. E-mail: tabataqy@hotmail.com
} 
observation, field notes and audio class recording as data collection tools. From these methodological procedures, we identified that the pre-service teachers mobilized pedagogical resources aligned with a mix of grammatical and communicative-based approach, since they make use of well-known structural practices, but in a contextualized and justified way. Finally, we understand that the recognition of a certain approach can help to clarify the practices of teachers and assist in the reflection of these actions seeking improvement of professional action.

KEYWORDS: Portuguese as a foreign language. Approach analysis. Pre-serviceteachers.

RESUMEN: A la luz de Almeida Filho (1997), Anthony (1963), Prabhu (1990) y otros, concebimos un abordaje como la filosofía con el potencial de guiar los procesos de enseñanza y aprendizaje de sus agentes. En este trabajo, buscamos analizar elementos que puedan indicar el predominio de abordajes en el proceso de enseñanza de PLE, a través de concepciones sobre la enseñanza del lenguaje señaladas por los docentes en formación, así como el desempeño de estos agentes en un proyecto de extensión de una universidad pública en el interior de São Paulo. Teniendo esto en cuenta, apoyadas por el paradigma cualitativo-interpretativo, utilizamos cuestionarios semiestructurados, observación de clase, notas de campo y grabación de clase en audio como herramientas de producción de datos. A partir de estos procedimientos metodológicos, identificamos que los docentes en formación movilizaron recursos pedagógicos alineados con el abordaje Gramatical Comunicativizado, ya que hacen uso de prácticas estructurales reconocidas, pero de forma contextualizada y justificada. Entendemos que el reconocimiento del abordaje puede ayudar a aclarar las prácticas de los maestros y, a su debido tiempo, ayudar a reflexionar sobre estas acciones en busca de la mejora de la acción profesional.

PALABRAS CLAVE: Portugués lengua extranjera. Análisis de abordaje. Docentes en formación.

\section{Introdução}

O ensino-aprendizagem de Português como Língua Estrangeira (PLE) teve seu início no Brasil em aproximadamente 1956 com a publicação do primeiro livro didático, "O Ensino de Português para estrangeiros", de Mercedes Marchandt, desenvolvido para suprir as necessidades da área naquela época. Entretanto, somente nas últimas décadas é que o ensino de língua portuguesa para estrangeiros despontou de fato. Considerando que o Brasil é o país que possui hoje o maior contingente de falantes nativos de língua portuguesa (EBERHARD; SIMONS; FENNIG, 2020), o esforço educacional, cultural e político empreendido no país tem tido grande peso para a promoção da lusofonia. Levando em consideração essa crescente demanda pelo ensino do português na condição de língua estrangeira, instituições vêm ofertando disciplinas ${ }^{2}$ ou até mesmo licenciaturas com habilitação específica ${ }^{3}$ nessa área a fim de se formar profissionais aptos a atuarem nesse meio.

\footnotetext{
${ }^{2}$ A saber: Universidade Federal de São Carlos, Universidade Federal do Rio Grande do Sul, Universidade Federal Fluminense, Universidade Federal do Rio de Janeiro.

${ }^{3}$ A saber: Universidade de Brasília, Universidade Federal da Bahia, Universidade Federal de Integração LatinoAmericana, Universidade Estadual de Campinas.
} 
Diante do exposto, este trabalho tem por objetivo investigar percepções sobre ensino e ações pedagógicas de professores em formação (doravante PEF) em Letras com habilitação em língua estrangeira, que cursam a disciplina Ensino de Português para Estrangeiros em uma universidade do interior paulista. Especificamente, buscamos identificar traços de abordagens predominantes subjacentes à prática de dois PEF que lecionam um curso de português para estrangeiros, o qual é vinculado ao instituto de línguas da mesma universidade.

Compreendemos "abordagem" como o fio condutor que orienta os processos de ensinar e de aprender de seus agentes (ALMEIDA FILHO, 1997; ANTHONY, 1963; PRABHU, 1990). Assim, como bem assinala Almeida Filho (2012), entendemos que a abordagem que rege o exercício do profissional de PLE pode se materializar em quatro dimensões: planejamento, produção/seleção de material didático, experiência em sala com e na língua-alvo e avaliação.

No intuito de encontrarmos elementos indicativos de abordagens do processo de ensino-aprendizagem de PLE desses professores, coletamos dados a partir dos seguintes instrumentos: questionário, observação de aula, notas de campo e gravação de aula em áudio e, posteriormente, triangulamos os dados para análise. Os resultados desta pesquisa podem ajudar a esclarecer práticas de professores em formação no que tange ao ensino de PLE e, oportunamente, auxiliar na reflexão dessas ações em busca do aprimoramento da ação profissional.

Na próxima seção, fazemos um breve histórico sobre a área de Português como Língua Estrangeira. Em seguida, discutimos o conceito de abordagem de ensino, dando maior destaque para as abordagens consideradas neste trabalho. Mais adiante, descrevemos a metodologia de pesquisa utilizada, apresentando o cenário que embasa a pesquisa e os procedimentos metodológicos realizados. Na seção seguinte, apresentamos a análise das aulas observadas e uma discussão dos resultados. Por fim, desenvolvemos algumas considerações finais sobre a pesquisa.

\section{Português como Língua Estrangeira}

Optamos pelo uso da nomenclatura PLE reconhecendo que este termo tem sido usado de forma mais geral para denominar a área que envolve a pesquisa e o ensino de português como uma nova língua a falantes de outras línguas. Conforme afirma Almeida 
Filho (2011), no Brasil, o início dessa área tem como marco simbólico a publicação do livro didático "O Ensino de Português para Estrangeiros", de Mercedes Marchandt, no ano de 1956. Mais tarde, em 1978, surge uma série brasileira de livros chamada "Português do Brasil para Falantes de Espanhol", publicada por Francisco Gomes de Matos e Sônia Biazioli. No intervalo entre uma publicação e outra, consideramos relevante citar a considerável produção de livros em universidades dos Estados Unidos, marcada pela inserção do português como língua estrangeira no país.

Além dessas publicações, o período foi marcado também pela criação de instituições promotoras do português mundo afora, como é o caso dos Centros de Estudos Brasileiros e postos de leitorado. Por fim, marcando o ápice do PLE, contamos com a criação pelo MEC do Exame Nacional de Proficiência em Português (Celpe-Bras), aplicado pela primeira vez em 1998 (INEP, 2020).

O surgimento desta nova área, e consequentemente de novas ações, "nos leva a indagar, de imediato, qual o grau de prontidão do Brasil para oferecer o ensino da língua portuguesa como uma nova língua a falantes de outros idiomas" (ALMEIDA FILHO, 2009, p. 2). Reconhecendo a importância da formação inicial de profissionais para essa área, inicialmente, segundo Almeida Filho (2009), é necessário obter a formação em Letras, habilitar-se em uma língua estrangeira específica e cursar uma disciplina preparatória para o ensino de PLE, agregada a uma introdução à Linguística Aplicada. Adicionamos a essas qualificações, a necessidade da prática ainda em período de formação, pois entendemos que esses momentos permitem ao professor em formação a reflexão, "parte nevrálgica de uma competência profissional em movimento" (ALMEIDA FILHO, 2011, p. 26).

Tendo em vista esse cenário de formação profissional, desenvolvemos este trabalho buscando refletir sobre a operacionalização de conhecimentos teóricos e metodológicos por professores em formação em sala de aula de PLE. Mais especificamente, objetivamos investigar se a abordagem declarada pelos PEF e a abordagem emergente da prática estão em alinhamento, bem como apresentar indícios que esclareçam/apontem convergências ou divergências à abordagem eleita. 


\section{Abordagens de ensino de línguas}

É comum encontrarmos tanto em produções acadêmicas como em conversas casuais com professores de línguas estrangeiras o termo "abordagem" sendo utilizado como sinônimo de método. No entanto, há autores que defendem a distinção entre esses termos, tal como já sinalizado por Anthony em 1963. De acordo com esse autor, a abordagem, os métodos e as técnicas formam o processo de ensino-aprendizagem de línguas, em que a abordagem ocupa uma posição hierarquicamente superior, seguida de métodos e técnicas, respectivamente. Prabhu (1990) corrobora tal perspectiva ao afirmar que a abordagem antecede a escolha de métodos, sendo a primeira considerada como a compreensão subjetiva do professor acerca do seu próprio ensino.

Desenvolvemos este trabalho guiando-nos a partir da definição proposta por Almeida Filho (1997, p. 21) de que a abordagem é "uma força sintética, potencial, proveniente de um conjunto nem sempre harmônico de crenças, pressupostos e princípios, que nos faz atuar de maneira específica em nossas salas de aula". Nessa perspectiva, a partir do reconhecimento da abordagem de professores, é possível (re)conhecer porque ensinamos do modo como ensinamos.

Almeida Filho (1997) assevera que a abordagem pode ser rastreada por meio de pistas no trabalho do profissional que apontam para suas concepções (mais implícitas ou mais formais, dependendo de cada história de vida) sobre língua(gem)/língua estrangeira, aprender línguas e ensinar uma nova língua. A partir da análise das concepções e das práticas dos professores em formação, buscamos traçar seus perfis e verificar com qual das duas macroabordagens, a gramatical ou a abordagem comunicativa, esses profissionais dialogam com mais preponderância, uma vez que essas abordagens foram amplamente discutidas nos encontros com o ministrante da referida disciplina. Além disso, buscamos verificar a convergência entre a abordagem declarada pelos PEF (via questionário) e a abordagem que emerge a partir da prática.

Em consonância com Almeida Filho (1997), compreendemos que a análise de abordagem pode ser auxiliada pelo reconhecimento dos papéis e atitudes dos professores em sala de aula. Tomando a abordagem como a força que sustenta e orienta o processo de ensino-aprendizagem de LE, compreendemos que ela está, portanto, hierarquicamente acima de métodos e técnicas de ensino de LE. Desse modo, a abordagem materializa-se com o apoio das quatro dimensões, sendo elas: (i) 
planejamento; (ii) seleção/produção de material didático; (iii) procedimentos, recursos e estratégias em sala de aula e (iv) avaliação.

Admitimos que o reconhecimento de uma abordagem subjacente a certas aulas observadas não é tarefa fácil, pois uma análise consistente de abordagem requer certo tempo em campo. Todavia, apesar das dificuldades, lançamo-nos na empreitada a fim de contribuir para o processo de reflexão da prática desses professores, bem como refletir sobre nossas próprias práticas como docentes de PLE, pois consideramos que a formação é, essencialmente, dialógica e contínua. Compreendemos, assim, que "é necessário que o processo de formação de professores de línguas seja sustentado teoricamente, para que possam[os] atuar de maneira emancipada, sabendo explicitar e explicar o fazer." (VIANA, 2020, p. 11).

Nas subseções seguintes, trataremos das duas macroabordagens, a Gramatical e a Comunicativa, e também da abordagem Gramatical Comunicativizada, considerada aqui como um resultado da hibridez das duas primeiras, nomenclatura encontrada em trabalhos na área de ensino de línguas, tais como em Abrahão (2015), Campos (2007), Macêdo (2016), dentre outros.

\section{Abordagem Gramatical}

Almeida Filho (2011) levanta argumentos favoráveis e desfavoráveis quanto ao ensino focado na estrutura de uma nova língua. Em outras palavras, ele questiona se o ensino da língua pela língua - compartimentação das regras e formas gramaticais - é realmente suficiente para que a aprendizagem ocorra de forma efetiva.

O conceito de língua não poderia ser de outra maneira, dada a visão de linguagem dominante no século XIX. No entanto, a gramática como um caminho de aprender línguas recebeu diversos ataques sobre seu valor no processo de ensino-aprendizagem:

Antes, confiávamos na ideia de que outra língua só poderia ser aprendida com consciência, racionalmente. Adquirir estava reservado às crianças muito pequenas. Os adultos perdiam para sempre o poder de adquirir novas línguas tendo de se conformar apenas com o aprender pela consciência das regras facilitadas pedagogicamente, contextualizadas e fartamente praticadas (ALMEIDA FILHO, 2011, p. 82).

De modo geral, a Abordagem Gramatical (AG) é fortemente marcada pela 
organização de conteúdos e atividades com objetivos preponderantemente gramaticais. Freitas e Barbirato (2020) indicam outras características dessa abordagem, tais como a apresentação de língua de forma fragmentada, uso recorrente da língua materna do aprendente, o material didático como "propiciador de baixa interação" e a "obsessão pela pronúncia nativa perfeita" (FREITAS; BARBIRATO, 2020, p. 59).

Professores e aprendentes filiados a essa concepção de abordagem tendem a compreender que o processo de ensino-aprendizagem de uma LE de maneira satisfatória só ocorre mediante exposição gramatical sistematizada. Em outras palavras, o foco será na compreensão da língua enquanto sistema, que corresponde a um despedaçamento em níveis fonético-fonológicos, lexicais, sintáticos e morfológicos de modo descontextualizado e sem vistas à interação.

\section{Abordagem Comunicativa}

A Abordagem Comunicativa (AC) pode ser interpretada de maneiras distintas, de acordo com a filiação teórica que um(a) autor(a) decide tomar para seu enfoque. Podemos afirmar que um dos pontos fortes dessa abordagem é de desestruturar zonas de conforto modeladas no e pelo estruturalismo, porquanto obriga o professor a planejar novos cursos, criar novos materiais a fim de promover atividades distintas em sala e, por fim, avaliar coerentemente rendimento e proficiência. A AC tem como seu elemento principal o sentido e não a forma.

Para este trabalho, baseamo-nos numa série de posturas e ações comunicativas indicadas por Almeida Filho (2005):

- Significação e relevância dos conteúdos: o aprendente precisa reconhecer a validade dos exercícios propostos para a prática da língua;

- Utilização de uma nomenclatura comunicativa nova;

- Tolerância explícita: tanto com o uso da língua materna como mediadora na aprendizagem de outra língua, como também considerando os erros como um "sinal de crescimento da capacidade de usar a língua-alvo" (ALMEIDA FILHO, 2005, p. 79);

- Aceitação de exercícios mecânicos de substituição: especialmente para racionalizar a prática de elementos frasais ou lexicais com vistas a facilitar a autonomia do aprendente; 
- Garantia de condições para a aprendizagem: o método de ensino do professor(a) ('técnicas e recursos audiovisuais', materiais paradidáticos e gramáticas pedagógicas);

- Representação de temas: problematização de temas e conflitos do universo do aluno, partindo da premissa de que o planejamento das atividades e seus temas partem da busca prévia do que é importante para os próprios aprendentes;

- Atenção às variáveis afetivas;

- Avaliação do progresso ou da proficiência.

A AC mantém uma relação estreita com o conceito de competência comunicativa (CC) e isso significa dizer que a ênfase desta abordagem é muito mais voltada ao que tem sentido para o aprendente do que, exclusivamente, à explicitação e conformação com as regras e a forma da língua. A CC surge não como um rompimento total ao estruturalismo anterior, mas sim como o rompimento de um sistema puramente gramatical, que prioriza as regras em detrimento das necessidades dos contextos de uso da língua. $O$ construto auxilia tanto aprendente como professor a desenvolverem suas competências.

O aprendente pode desenvolver sua CC quando o professor também lança mão da criação de ambientes favoráveis ao aprendizado na língua-alvo com a apresentação de situações reais de uso da língua e uma abordagem que as possibilite, tornando a aula mais atraente. A abordagem comunicativa não é, pois, "uma bateria de técnicas ou um modelo de planejamento, mas sim a adoção de princípios mais amplos como o foco no processo, nas maneiras específicas de como se aprende e de como se ensina outra língua" (FRANCO; ALMEIDA FILHO, 2009, p. 18).

\section{Abordagem Gramatical Comunicativizada}

A Abordagem Gramatical Comunicativizada (AGc) não é considerada neste trabalho como uma nova abordagem, ou melhor dizendo, não é oficialmente considerada uma macroabordagem, como a Gramatical ou a Comunicativa, mas é resultante da mescla dessas. Abrahão (2015, p. 29), ao se referir a uma interpretação da abordagem comunicativa, pondera que ela é comunicativizada quando pretende "dar ao estruturalismo uma roupagem nova, apenas comunicativizando uma ou outra tarefa, sem 
alterar concepções básicas de linguagem, de ensinar e de aprender.". Um exemplo dessa prática, sugerido por Abrahão (2015), seria adotar um livro didático gramatical, mas introduzir jogos e músicas para se trabalhar a língua de uma forma mais comunicativizada.

Em consonância com Santos e Almeida Filho (2011, p. 108), entendemos que há duas possibilidades para a AGc:

(1) não fazer a transição preferindo apenas escamotear a gramaticalidade central a que se filia, ou (2) não pretende fazer a travessia completa e imediata de uma abordagem para outra preferindo uma lenta, gradual e segura transição adotando aspectos da filosofia da comunicação para o aprendizado de idiomas, mantendo confortavelmente ainda a gramática como seu princípio organizador de toda a operação de ensinoaprendizagem.

Freitas e Barbirato (2020, p. 59) apontam características recorrentes de abordagem gramatical comunicativizada, a saber: "organização por conteúdos (forma); atividades que, mesmo com objetivos gramaticais, permitem maior interação; professor que delega responsabilidades aos alunos; as ações do professor que se alternam entre o tradicional (gramatical) e o comunicativo; as atividades do livro didático que alternam entre forma e significado".

Apresentadas as abordagens selecionadas para análise deste estudo, trazemos em seguida a metodologia de pesquisa desenvolvida que sustentou nosso percurso investigativo.

\section{Metodologia de pesquisa}

Em vista dos objetivos propostos - de encontrar traços de abordagens de ensino de professores em formação - caracterizamos este estudo como qualitativo, orientado pela perspectiva interpretativista. Isso equivale dizer que fundamentamos nossa investigação a partir de interpretações da construção do meio social no qual interagimos, reconhecendo que as diversas variáveis que influenciam no processo de ensinar e aprender não são facilmente isoladas ou, ainda, hermeticamente selecionadas com vistas à medição ou ao estabelecimento de relações causais. Ao contrário, compreendemos o ensino-aprendizagem como processuais e, desse modo, consideramos pesquisa qualitativa como "[...] uma atividade situada que localiza o observador no mundo. 
Pesquisa qualitativa consiste em um conjunto de práticas interpretativas e materiais que tornam o mundo visível." ${ }^{\prime 4}$ (DENZIN; LINCOLN, 2018, p. 43).

Além de nos apoiarmos no paradigma qualitativo-interpretativista, este trabalho apresenta características de um estudo de caso, posto que focalizamos um sistema limitado, buscando a melhor compreensão desse caso pelo interesse despertado em nós como estagiárias em um contexto de formação de docentes, cientes de que não ilustramos uma amostragem cujos resultados poderiam ser generalizáveis, mas com o objetivo de que esses resultados possam ser úteis ao desenvolvimento de uma "generalização analítica" (YIN, 2016). Em outras palavras, informamos um determinado conjunto de construções teóricas com potencial aplicação para outras situações semelhantes. Baseando em Yin (2016), compreendemos que "[0]s resultados do estudo devem demonstrar se e como os resultados empíricos apoiaram ou desafiaram a teoria. ${ }^{15}$ (YIN, 2016, p. 10).

\section{Contextualização}

Os dados desta pesquisa foram gerados no âmbito da disciplina "Ensino de Português para Estrangeiros: Contextos e Práticas" (EPECOPS), oferecida de forma optativa aos graduandos do curso de Licenciatura em Letras em uma universidade do interior paulista. Essa disciplina tem a duração de um semestre letivo e conta com a carga horária semanal de duas horas teóricas e quatro horas práticas, totalizando semestralmente noventa horas.

As aulas teóricas são planejadas por seu professor titular, responsável por instruir os professores em formação em suas práticas pedagógicas, e aborda tópicos como o panorama do PLE no Brasil e no mundo, metodologias de ensino, planejamento de cursos, avaliação em língua estrangeira e preparação de material didático. As pesquisadoras deste trabalho atuaram no âmbito de estágio docente da referida disciplina, ora observando e ministrando aulas teóricas e colaborando com as discussões em grupo, ora participando de reuniões fora da sala de aula, por meio de sessões de monitoria, a fim

\footnotetext{
${ }^{4}$ Trecho original: "Qualitative research is a situated activity that locates the observer in the world. Qualitative research consists of a set of interpretive, material practices that make the world visible" (DENZIN; LINCOLN, 2018, p. 43).

5 Trecho original: "The study's findings should demonstrate whether and how the empirical results supported or challenged the theory" (YIN, 2016, p. 106).
} 
de auxiliar os PEF na elaboração de atividades e adequação dos planos de aula.

A parte prática da disciplina é viabilizada pela participação dos PEF em cursos de extensão de PLE, ofertado pelo Instituto de Línguas da mesma universidade. Para a composição das turmas, o professor titular solicitou que os próprios aprendentes se organizassem em duplas. É importante esclarecer que as turmas de PLE são divididas entre falantes de espanhol e falantes de outras línguas. Assim, há níveis básicos 1 e 2 para ambos os públicos - hispanofalantes e outras línguas - e somente a partir do nível Intermediário 1 é que não se faz mais distinção entre as línguas maternas.

Ao longo do estágio docente, tivemos a oportunidade de acompanhar diversas turmas, no entanto, optamos por focar nossa análise no nível Intermediário 1, uma vez que os PEF responsáveis por essa turma concordaram em participar da pesquisa e permitiram a nossa presença nas aulas. Ressaltamos que todos os níveis contam com planos de aula previamente elaborados por professores experientes em PLE; todavia, os PEF têm autonomia para alterar temas, recursos e estratégias, a depender da necessidade dos aprendentes, mas têm de seguir uma progressão linguística específica para que haja coerência na continuidade do processo no próximo nível a ser cursado.

Os participantes que integram esta pesquisa são dois professores em formação, o PEF1 e a PEF2, ambos em processo de finalização de suas licenciaturas. O PEF1 cursa licenciatura em letras com habilitação em português-inglês e apresenta experiência com ensino de língua inglesa, tendo ministrado curso nessa língua por dois anos. Já a PEF2 cursa licenciatura em letras com habilitação em português-espanhol e também tem experiência com ensino, tendo atuado como professora de espanhol como língua estrangeira.

A turma era inicialmente composta por 4 aprendentes: dois alunos hispanofalantes de Honduras e dois alunos indianos. No entanto, com o decorrer das aulas, um dos alunos indianos migrou de turma, que ficou reduzida a três participantes.

\section{Procedimentos metodológicos}

Para visibilizar o contexto do nosso estudo e investigar o fenômeno em questão, partimos do seguinte percurso de investigação para a produção dos dados: (i) participação em estágio supervisionado de capacitação docente em disciplina de 
graduação; (ii) produção dos dados em sala de aula; (iii) análise e discussão dos dados.

Para produção dos dados, utilizamos os seguintes instrumentos: observação de aulas, notas de campo, gravação das aulas em áudio e aplicação de questionário. Com relação à observação, Cunha (2007, p. 64) aponta que se trata de "ver e ouvir com atenção os atores do cenário de pesquisa, seguindo cuidadosamente suas ações. Não é só olhar e escutar, mas, na medida em que o fazemos, examinar criticamente os eventos relevantes e os fatos reincidentes". A observação consistiu em obter informações sobre o contexto de ensino: comportamentos e ações dos professores em sala de aula, bem como outros eventos que se mostraram relevantes.

A observação pode ser sistemática ou assistemática, participante ou nãoparticipante. Nesse sentido, Cunha (2007, p. 65) esclarece que a observação assistemática não-participante, também chamada de simples, ocorre quando "o pesquisador permanece alheio ao cenário e aos sujeitos de pesquisa, observando-os de maneira espontânea, não planificada. No caso da observação simples, é comum o pesquisador manter uma postura de espectador."

Optamos por realizar observação assistemática não-participante devido à imprevisibilidade do campo e, assim, não assumir de antemão o que encontrar nas práticas dos PEF, em que só o que é previsto é priorizado e, posteriormente, categorizado.

Realizamos observações em três momentos da prática dos PEF. O primeiro encontro ocorreu no dia 20 de setembro de 2018 a fim de conhecermos os participantes da pesquisa, tanto os PEF quanto os aprendentes. Como já mencionado, a turma foi constituída por três pessoas: dois hondurenhos e uma indiana. Eles integraram o curso no nível Intermediário I, com aulas ministradas duas vezes por semana, sendo que cada encontro teve a duração de 1h30min. No segundo encontro, observamos com mais atenção os indícios de abordagem de cada um dos PEF. No terceiro momento, por sua vez, fizemos gravação em áudio das interações e aplicamos um questionário aos PEF após o término da aula.

As observações foram registradas em notas de campo com o intuito de materializar percepções sobre as aulas para posterior análise e comparação entre as pesquisadoras. É válido mencionar que lançamos mão da triangulação de pesquisadores (YIN, 2016), levando em consideração que ambas as pesquisadoras, ao observarmos as mesmas aulas, desenvolvemos diferentes notas de campo. Isso facilitou a posterior comparação 
de notas para a discussão e análise de dados. As notas de campo foram escritas em ambiente formal de ensino e nelas foram registradas percepções acerca da concretização do planejamento do curso e dos procedimentos, recursos e estratégias utilizados em sala de aula de modo que nos auxiliasse a compreender suas possíveis abordagens.

Tomamos como base os pressupostos indicados por Fetterman (1998) ao esclarecer que o processo de escrita das notas de campo é distinto de um relatório etnograficamente sólido, pois a primeira modalidade tem um estilo cru (rawstyle), todavia tais notas precisam apresentar tanta clareza, concisão e integridade quanto um relatório. Ainda de acordo com o autor supracitado, o "objetivo é representar a realidade concisamente, mas de forma completa e não reproduzir cada palavra e detalhe. Uma reprodução completa não é possível nem desejável" (FETTERMAN, 1998, p. 123).

Outro instrumento utilizado foi a gravação de aula em áudio, que foi realizada apenas no terceiro encontro, visto que nos dois primeiros preferimos evitar um possível desconforto com a gravação. Por meio da gravação em áudio, assumimos poder haver mais exatidão do objeto de estudo que queríamos focalizar. Além disso, o conteúdo gravado poderia ser acessado a qualquer momento posterior à aula, o que nos ofereceria a possibilidade de (re)visitar e, possivelmente, encontrar detalhes que no instante da observação não poderiam ser identificados. Consideramos, ainda, que esse instrumento de produção de dados nos aproxima com melhor precisão da realidade dos acontecimentos.

A fim de buscar diferentes estratégias de coleta de evidências, recorremos também ao questionário misto, composto por 11 perguntas dispostas em abertas e fechadas. As perguntas são relacionadas à formação dos participantes, experiência com ensinoaprendizagem de línguas e perguntas norteadoras para a compreensão de sua(s) abordagem(ns). Com relação às potencialidades no uso dos instrumentos, selecionamos o questionário tanto pela flexibilização no tempo de resposta como também pela diminuição de influência das opiniões das pesquisadoras (CUNHA, 2007).

\section{Análise e discussão dos dados}

Nesta seção, levando em consideração as definições teóricas e apresentações contextuais já citadas ao longo deste trabalho, procedemos à descrição das aulas 
observadas, bem como a análise interpretativa empreendida. Segmentamos a discussão dos dados em três partes, tendo em vista a sucessão cronológica de cada aula observada.

\section{Primeira aula: familiarização com o contexto}

Os professores iniciaram a primeira aula observada utilizando projeção de slides com a temática "museus". O tema foi escolhido tendo em vista o incêndio do Museu Nacional do Rio de Janeiro no início de setembro de 2018, o qual foi amplamente noticiado pela mídia brasileira e considerado como relevante para a discussão em sala de aula. Após a exibição dos slides, houve a projeção de uma notícia sobre o tema e a solicitação de leitura em voz alta pelos aprendentes.

Na medida em que os PEF introduziam uma palavra que possivelmente seria nova para os aprendentes, eles a escreviam na lousa, explicando seu significado por meio de desenhos, mímicas e, em últimos casos, tradução para o inglês ou espanhol. Um exemplo dessa constatação foi quando a PEF2 usou a seguinte estratégia ao ser indagada sobre o vocábulo "arquiteta": "A arquiteta, a pessoa quem construiu o edifício, ela [...]". Conforme excerto retirado das notas de campo das pesquisadoras, a professora não precisou recorrer à língua de mediação (espanhol/inglês), pois a partir da explicação completamente em português, pôde esclarecer a dúvida. Essa estratégia é um indício de flexibilização metodológica dos professores que, considerando as necessidades dos aprendentes, proporcionam condições para a aprendizagem, conforme apontado por Almeida Filho (2005) sobre a postura do professor comunicativo. Esse oferecimento de condições para uma aprendizagem significativa é recorrente nas práticas desses professores, de modo que priorizam a experiência de ensinar e aprender ao invés de seguir um planejamento gramatical descontextualizado.

Outra estratégia que consideramos comunicativa é a correção indireta de pronúncia, como foi o caso do aluno de língua distante ao pronunciar a palavra "item" como / ' ar 'ţ̧/, evidenciando interferência da língua inglesa. Diante dessa ocorrência, os PEF não interromperam ou indicaram inadequação imediata, mas solicitaram a reprodução do vocábulo após o término da leitura do texto em questão.

Quanto à interação, é preciso, inicialmente, esclarecermos a particularidade do contexto. Consideramos, para este trabalho, três tipos de interação: PEF - pesquisadoras, 
PEF1 - PEF2 e interação entre os próprios aprendentes. A primeira interação formal ocorreu entre os PEF e as pesquisadoras deste trabalho ao discutirem sobre o plano de aula e as adequações necessárias para as aulas posteriores. Desse momento até o último dia de aula observado, pudemos constatar que a interação entre os PEF ocorreu de maneira amigável e respeitosa. É importante ressaltar que ambos primam pela alteração de turno de forma harmônica, ou seja, quando um professor detém o turno de fala, o outro aguarda o momento oportuno para intervir.

A interação entre os aprendentes também é considerada cordial, tendo em vista que a turma é composta por aprendentes de línguas tipologicamente distantes e próximas e, talvez, fosse esperado impaciência por parte dos hispanofalantes diante da notada dificuldade de comunicação na língua-alvo pela aprendente de língua distante (aprendente P).

\section{Segunda aula}

Inicialmente, os PEF retomaram brevemente o conteúdo da aula anterior para sanar possíveis dúvidas que pudessem ter surgido. Consideramos esse procedimento fundamental, pois possibilita a contextualização do conteúdo e também a oportunidade de revisitar pontos importantes das aulas anteriores. Essa tentativa de retomada do conteúdo ministrado entre os aprendentes pode ser entendida como resultado da experiência prévia de ambos os PEF, como explicaremos adiante.

Como mencionado na seção de contextualização deste trabalho, o PEF1 é proficiente em língua inglesa e tem experiência com o ensino dessa língua, enquanto a PEF2 é proficiente em língua espanhola e também experiente com o ensino dessa língua. Por esses motivos, há duas línguas de mediação em sala de aula e, dependendo da língua dominante do aprendente, o turno de fala é mais frequente com o PEF1 ou com a PEF2. Essa estratégia foi utilizada com muita frequência, sobretudo quando do uso da língua inglesa para minimizar os ruídos de compreensão da aprendente $P$.

Compreendemos que em determinadas circunstâncias é importante o uso da língua mediadora para esclarecer ruídos na explicação de determinado assunto, no entanto, esse recurso em excesso pode afetar a autonomia do aprendente, bem como colaborar com uma cultura de aprender dependente da tradução do professor. Ao recorrer às 
traduções constantes, entendemos que o fluxo conversacional é interrompido pelo uso de outra língua, quando na realidade isso poderia ser elucidado de uma forma simplificada na própria língua-alvo e, assim, aumentar a quantidade de insumo em português.

Em relação à interação entre os PEF e os aprendentes, notamos em dado momento que o PEF1 ministrava a aula para uma parcela da turma e a PEF2 para a aprendente P, paralelamente. Isso ocorreu porque a aprendente em questão não havia comparecido à última aula e os professores entenderam que seria importante a contextualização para o desenvolvimento do conteúdo. Essa atenção especial voltou a ocorrer outras vezes, mesmo que de forma distinta, contribuindo para o distanciamento da aprendente $\mathrm{P}$ do restante da turma.

Tal distanciamento também ocorre, em nossa avaliação, nas diversas vezes em que os PEF se dirigiram estritamente à aprendente $\mathrm{P}$ perguntando se ela havia compreendido, como pode ser verificado no excerto extraído das notas de campo das pesquisadoras: "A aluna de língua distante claramente não segue o mesmo fluxo. Constantemente o professor pergunta 'entendeu, P?"'. Julgamos importante confirmar o acompanhamento do desenvolvimento da aula por todos os aprendentes, porém a constante exposição de um aprendente em detrimento dos outros pode aumentar o filtro afetivo do primeiro e até causar constrangimento.

\section{Terceira aula}

Na terceira e última aula observada, pudemos confirmar a estratégia utilizada pelos PEF de retomar o conteúdo e também de oportunizar momentos para esclarecimento de dúvidas ao exibir novamente a apresentação de slides da aula anterior, como verificado nos trechos: "Começaram a aula retomando a aula anterior (atividade 4)" e "Retomam o power point da aula anterior", extraídos das notas de campo das pesquisadoras. Na sequência, apresentaram um quadro comparativo sobre estruturas condicionais nas três línguas - português, inglês e espanhol. É importante esclarecer que os aprendentes demonstraram muita dificuldade com o conteúdo em questão, iniciado na aula anterior. Diante disso, os PEF solicitaram auxílio das pesquisadoras para o desenvolvimento desse quadro, que é considerado tanto uma ação resultante da análise de necessidades dos aprendentes como da reflexão dos PEF sobre suas próprias 
atuações.

Outra proposta com o objetivo de praticar o conteúdo foi a atividade de completar lacunas, comumente utilizada como um recurso amparado pela abordagem gramatical. Nesse caso, essa atividade apresentou indícios de ambas as abordagens - gramatical e comunicativa - e entendemos, assim, que esteja alinhada à abordagem gramatical comunicativizada. O motivo dessa hibridez dá-se por dois aspectos: ela não é completamente gramatical porque o objetivo final não é a compreensão descontextualizada de determinada estrutura gramatical, já que os exemplos partem de um contexto resultante de produções anteriores dos próprios aprendentes, ou seja, da interação real destes, e a construção de atividades a partir dessas situações nãosimuladas pode ser considerada indício da abordagem comunicativa.

Apesar do esforço de comunicativização, a atividade também apresentava frases isoladas, descontextualizadas da temática da aula anterior. Ainda com relação à atividade sobre lacunas, percebemos dois equívocos: primeiramente havia alguns erros de acentuação que foram evidenciados pelos PEF, mas não foram corrigidos imediatamente. Outra questão foi a solicitação de preenchimento de lacunas com verbos em modo distinto do foco da aula.

Uma estratégia de esclarecimento de conteúdo, a nosso ver bem utilizada pelo PEF1, foi o uso de recurso visual para elucidar a diferença entre artigos definidos e indefinidos, como destacado em notas de campo das pesquisadoras a seguir: "PEF1 usa recurso visual do desenho para explicar o uso do indefinido e definido". Além disso, em momento oportuno, sistematizou a pronúncia dos sons encontrados nas palavras do inglês que terminam em / ən/ (action, function, proportion) e comparou-as ao som do grafema "ção" do português, como podemos observar na seguinte transcrição de áudio: "sempre que você tiver um verbo que tem, por exemplo, 'action', 'function', [...] 'proportion '[...], a gente costuma trocar esses t's por um som sibilante, por um 's': ação, função, proporção; e esse 'on', a gente costuma fazer um 'ão'".

Assim como no início da aula, os PEF recorreram à língua estrangeira de mediação a pedido dos aprendentes e não de forma assistemática, sendo um meio para atingir um determinado objetivo e não um fim. Além disso, não fizeram uso de linguagem metalinguística excessiva, por exemplo, não citaram diretamente elementos de gramática, mas explicaram seu uso em situações de interação. Esses casos foram 
registrados em notas de campo, e trazemos como exemplo no excerto a seguir: "Em nenhum momento citaram o nome da forma verbal "futuro do pretérito". Sempre explicaram a estrutura dando o objetivo (para elaborar hipóteses, possibilidades)". Além desse registro, apresentamos outro exemplo também retirado das notas de campo: "A PEF2 explicou a diferença das palavras "reclamasse" e "reclamação" sem citar a terminologia gramatical "verbo" e "substantivo/nome"'". Compreendemos que essa estratégia pode, aparentemente, ser caracterizada por traços de abordagem comunicativa. Uma amostra dessa escolha foi quando a PEF2 aproveitou de uma situação real em sala de aula - momento em que o vento bateu a porta da sala - para explicar o subjuntivo, conforme excerto a seguir, transcrito da gravação em áudio: "Se eu tivesse prendido a porta na parede, ela não teria batido".

A interação entre PEF e aprendentes ocorreu de forma tranquila, sem ruídos que nos chamaram atenção, à exceção da chegada do aprendente hondurenho (aprendente C) com atraso de 25 minutos, o qual, diferentemente da aprendente P na aula anterior, não recebeu atenção especial ou contextualização do conteúdo. Acreditamos que essa atitude pode ser explicada pelo fato do distanciamento tipológico da língua materna (LM) dos aprendentes, dando por certo que o aprendente $\mathrm{C}$, por ter a LM próxima do português, o espanhol, não apresentaria maiores dificuldades.

Em relação à interação entre os próprios aprendentes, julgamos ser pertinente relatar o episódio em que aprendentes $\mathrm{C}$ e $\mathrm{P}$ demonstraram dificuldade com o som nasal do português e, diante da situação, riram de forma prazerosa indicando certo coleguismo entre eles, como constatado pelas pesquisadoras no seguinte excerto de notas de campo: "Ambos alunos compartilham a dificuldade do som nasal ão (e riem - clima aparente agradável)". Além disso, $\mathrm{o}$ aprendente $\mathrm{C}$ auxiliou a aprendente $\mathrm{P}$ em diversos momentos da aula, já que a outra aprendente hispanofalante (amiga do aprendente $\mathrm{C}$ ) não havia comparecido.

Na parte final da aula, os PEF propuseram uma atividade de exibição de imagens de catástrofes ao redor do mundo e solicitaram que os aprendentes expressassem oralmente as palavras que viessem à mente ao observá-las. Esse momento pode ser considerado como uma tentativa de "criação de oásis", termo cunhado por Almeida Filho para se referir à vivência com e na língua-alvo e, portanto, um proeminente traço de abordagem comunicativa. 


\section{Traços de abordagens}

Como dito no início deste trabalho, não pretendemos e nem podemos afirmar a filiação de abordagem dos PEF, haja vista o curto período de observação de aulas, além de não termos acompanhado o processo do início ao fim. Tendo isso em vista, discutiremos a seguir aspectos indicadores de abordagem e contrastaremos as informações indicadas no questionário aplicado aos PEF com a prática em sala de aula. Em outras palavras, analisaremos a abordagem declarada e a abordagem que parece emergir a partir da prática.

Inicialmente notamos que a experiência prévia dos professores com ensino de língua estrangeira contribuiu em diversos momentos para a dinamização das aulas de PLE e, também, para o uso de recursos e estratégias para elucidação de dúvidas e exposição de novos conteúdos. Devido à nossa experiência no estágio docente com observação de outras turmas, pudemos notar que professores sem experiência prévia demonstraram maiores dificuldades desde o planejamento de aula até sua execução, enquanto os PEF em questão demonstraram mais autonomia no planejamento da aula, escolha do material didático e procedimentos utilizados em sala de aula.

Consideramos, ainda, relevante apontar que as disciplinas formadoras para o ensino de $L E$, tais como Linguística Aplicada e a própria disciplina de Ensino de Português para Estrangeiros, contribuíram para o autoconhecimento como futuros professores de línguas e para subsidiar as noções principais que norteiam o trabalho do professor, garantindo, assim, uma reflexão apropriada da prática docente. Como assevera Almeida Filho (2014, p. 25) sobre a competência profissional/acadêmica, "essa capacidade de integrar racionalidade ao processo [...] é também reflexiva, invoca constantemente o pensar, tolerando-Ihe os incômodos da insegurança que alguma crise instalada provoque temporariamente". Nesse sentido, Viana (2020, p. 12) indica que a relevância de análises de abordagem "consiste no fato de que esse procedimento de pesquisa permite ampla compreensão sobre a própria teorização na área, sobre formação de professores e sobre a prática pedagógica".

Partindo do pressuposto de que o processo de ensinar e aprender é direcionado por meio das visões que possuem sobre o que é língua(gem) e sobre o próprio processo, 
buscamos compreender esses conceitos a partir das respostas do questionário. O conceito de língua(gem) para a PEF2 foi descrito como "[...] um modo de sociabilidade entre os humanos, que se vincula/articula com aspectos culturais, políticos e históricos.", conquanto para o PEF1 "[...] é um sistema de comunicação, um espaço cognitivo em que alguém pode mediar pensamentos, expressões, sentimentos através de um signo.". Compreendemos que, para ambos, em gradações diferentes, a língua é considerada para além dos conhecimentos do sistema de seu funcionamento, já que perpassa os aspectos culturais e sócio-históricos de sua formação e tais perspectivas se aproximam mais da AC.

Outro conceito importante a ser considerado é sobre o que é ensinar-aprender línguas na perspectiva dos professores. Para a PEF2 "O ensino-aprendizagem de línguas perpassa por noções da língua como estrutura, mas sua centralidade deve ser a comunicação em si" e, para o PEF1, é tida como "Um processo em que o professor desenvolve um ambiente propício para a aprendizagem do aluno, proporcionando também a inversão de papéis numa via de mão dupla de saberes.". De fato, essas afirmações parecem se confirmar na prática, pois os PEF não priorizam o ensino da língua pela língua, ou seja, estritamente sua forma (AG), mas buscam desenvolvê-la a partir de contextos linguísticos para a prática social (AC).

Além disso, mobilizam e valorizam os conhecimentos a partir da contribuição dos aprendentes e, assim, inserem-nos ativamente no processo de ensino-aprendizagem, caracterizando a 'via de mão dupla 'mencionada pelo PEF1, ou seja, a partir de uma perspectiva dialógica. Segundo Almeida Filho (2012), uma visão de ensinar (ou de aprender) língua necessita, portanto, que os conhecimentos implícitos ou explícitos sejam convertidos numa capacidade real de ação/de ensino ou aprendizagem da língua-alvo.

Como o foco desta pesquisa é a análise de abordagem, interessou-nos conhecer a perspectiva dos PEF sobre sua definição. Para a PEF2, abordagem "É a escolha metodológica que se faz para ensinar/lecionar" e, para o PEF1, "seria um fio condutor que norteia as etapas do ensino-aprendizagem, desde a identificação das necessidades dos alunos até a avaliação.". Além disso, ambos selecionaram a opção da abordagem Gramatical Comunicativizada como norteadora de seus processos.

De acordo com a resposta fornecida no formulário, a PEF2 parece não distinguir com clareza o conceito de abordagem e metodologia e tal indistinção, conforme já 
mencionado anteriormente, é muito comum entre professores. Em contrapartida, o PEF1 parece se alinhar com mais propriedade aos pressupostos teóricos fundantes do conceito de abordagem. Ainda que a PEF2 não diferencie com clareza teórica os dois conceitos, sua escolha pela AGc reflete conhecimentos formais e informais.

Na pergunta 9 do questionário, os PEF foram convidados a enumerar de 1 a 4, em grau de importância, as quatro dimensões em referencia à Operação Global de Ensino de Línguas (OGEL), cunhada por Almeida Filho. Coincidentemente, ambos os PEF enumeraram todas as dimensões com o número 1 , indicando igual importância a todas elas, justificando que "Acredito que esses elementos se articulam e se pressupõem. Planejar o curso implica pensar as estratégias, o material didático, a avaliação, etc. (PEF2)" e, justificativa similar foi a do PEF1 ao escrever que "Todos os processos são igualmente importantes para que haja coerência no processo de ensino-aprendizagem." De maneira geral, essa escolha de enumeração equitativa reflete maturidade teórica relevante para professores em formação.

Reiteramos que os planos de aula foram elaborados previamente e que a progressão linguística proposta deveria ser seguida pelos PEF. Essa questão, contemplada na segunda etapa do processo da OGEL, nomeadamente "produção e/ou escolha do material didático", pode ter direcionado a preparação das aulas para uma abordagem mais inclinada a contemplar a estrutura da língua e, consequentemente, influenciado na condução das aulas desses professores em formação.

Diante das características que nos auxiliaram a reconhecer as abordagens subjacentes às práticas dos professores em formação, podemos identificar, ainda que minimamente, a predominância da AGc, a qual compreendemos não ser uma nova abordagem, mas sim o resultado da mescla das duas macroabordagens citadas anteriormente. 


\section{Considerações finais}

Este trabalho é resultado da participação no estágio de docência em uma disciplina de graduação que oportuniza a prática de ensino de Português como Língua Estrangeira. Por meio de observação da prática em sala de aula, notas de campo, gravação de aula e aplicação de questionário identificamos que as práticas pedagógicas dos participantes desta pesquisa, professores em formação, estão mais afinadas com a Abordagem Gramatical Comunicativizada.

Chegamos a essa constatação porque observamos o uso de recursos evidentes da Abordagem Gramatical, porém operacionalizados de forma contextualizada e justificada diante das circunstâncias, avançando para uma perspectiva de língua como ação social e, portanto, alinhados à Abordagem Comunicativa. Equivale dizer que o foco, de forma geral, não foi a prática metalinguística do funcionamento da língua e sim eventuais sistematizações para seu uso.

Reconhecemos a fragilidade da análise, já que nos restringimos a observar apenas três aulas, no entanto, é importante esclarecer que nos preocupamos em não causar constrangimento entre os PEF participantes desta pesquisa e os aprendentes. Para isso, optamos por frequentar aulas de outros PEF a fim de selecionar a turma que demonstrasse estar mais aberta à pesquisa, garantindo maior confiabilidade ao estudo. Essa preocupação se deve justamente por se tratar de professores que estão em formação.

Por sermos responsáveis pelo acompanhamento pedagógico desses professores, mantivemos diálogo constante dentro e fora da sala de aula, especialmente no contraturno das aulas de PLE, por meio de monitoria, e durante a disciplina de graduação, já que esse era o momento em que os PEF relatavam suas impressões e dúvidas emergidas a partir da prática.

Nesse sentido, como professoras em constante formação, avaliamos que uma análise de abordagem requer mais tempo em campo tanto para maior coleta de evidências quanto para nosso amadurecimento teórico. Compreendemos que a reflexão produzida a partir da análise seja relevante para o fomento de práticas colaborativas entre pesquisador-professor e, consequentemente, para a formação dos participantes desta pesquisa, sobretudo, por mobilizar autorreflexão sobre sua prática docente. Como 
indicativo para pesquisas futuras, registramos a necessidade de viabilização de aproximações entre teoria e prática na formação de professores, de modo que avanços teóricos cheguem à sala de aula de LE.

\section{Referências}

ABRAHÃO, Maria Helena Vieira. Algumas reflexões sobre a abordagem comunicativa, 0 pós-método e a prática docente. Revista Entrelínguas, Araraquara, v. 1, n. 1, p. 25-41, set. 2015. Disponível em:

https://periodicos.fclar.unesp.br/entrelinguas/article/view/8051. Acesso em: 27 mar. 2020.

ALMEIDA FILHO, José Carlos Paes de. A abordagem orientadora da ação do professor. In: ALMEIDA FILHO, José Carlos Paes (org.). Parâmetros atuais para o ensino de português língua estrangeira. Campinas: Pontes, 1997. p. 13-28.

ALMEIDA FILHO, José Carlos Paes de. A operação global de ensino de línguas e o modelo OGEL. In: ALMEIDA FILHO, José Carlos Paes de. Quatro estações no ensino de línguas. Campinas: Pontes, 2012. p. 9-30.

ALMEIDA FILHO, José Carlos Paes de. Ensino-aprendizagem de português como LE e L2: Fundamentos de abordagem e formação. In: ALMEIDA FILHO, José Carlos Paes de. Fundamentos de abordagem e formação no ensino de PLE e de outras línguas. Campinas: Pontes, 2011. p. 11-37.

ALMEIDA FILHO, José Carlos Paes de. Linguística aplicada: ensino de línguas e comunicação. Campinas: Pontes Editores e ArteLíngua, 2005.

ALMEIDA FILHO, José Carlos Paes de. O português como língua não-materna: concepções e contextos de ensino. Museu da Língua Portuguesa Estação da Luz. São Paulo, 2009. Disponível em:

http://www.museudalinguaportuguesa.org.br/colunas_interna.php?id_coluna=4. Acesso em: 16 out. 2018.

ALMEIDA FILHO, José Carlos Paes de. Sobre competências de ensinar e de aprender línguas. In: ALMEIDA FILHO, José Carlos Paes de (org.). Competências de aprendizes e professores de línguas. Campinas: Pontes, 2014. p. 11-34.

ANTHONY, Edward. Approach, method, and technique. English Language Teaching. London, v. 17, p. 63-67, jan. 1963.

CAMPOS, Ticiana Ribeiro. Forças de abordagens em busca de uma equação de ensinar e aprender LE. 2007. 88 f. Dissertação (Mestrado em Linguística Aplicada) Universidade de Brasília, Brasília, 2007. 
CUNHA, Maria Jandyra Cavalcanti. Pesquisa aplicada na área de português para falantes de outras línguas: procedimentos metodológicos. In: ALMEIDA FILHO, José Carlos Paes de; CUNHA, Maria Jandyra Cavalcanti. (org.). Projetos iniciais em português para falantes de outras línguas. Campinas: Pontes, 2007. p. 57-85.

DENZIN, Norman; LINCOLN, Yvonna (ed.). The SAGE handbook of qualitative research. $5^{\text {th }}$ ed. Thousand Oaks: Sage Publications, 2018.

EBERHARD, David M.; SIMONS, Gary F.; FENNIG, Charles D. Ethnologue: languages of the world. 2020. Disponível em: https://www.ethnologue.com/country/BR/languages. Acesso em: 21 set. 2020.

FETTERMAN, David. Ethnography: step by step. London: Sage, 1998.

FRANCO, Marilda Macedo Souto; ALMEIDA FILHO, José Carlos Paes. O conceito de competência comunicativa em retrospectiva e perspectiva. Revista Desempenho, Brasília, v. 1, n. 11, jun. 2009.

FREITAS, Mirelle da Silva; BARBIRATO, Rita de Cássia. Apontamentos da pesquisa nacional sobre o construto de abordagem. In: FREITAS, Mirelle da Silva; ORTALE, Fernanda Landucci (org.). Estudos de abordagem no ensino de línguas e formação docente. Campinas: Pontes, 2020. p. 47-69.

INEP - Instituto Nacional de Estudos e Pesquisas Educacionais Anísio Teixeira. Documento base do exame Celpe-Bras. Brasília: INEP, 2020.

MACÊDO, Camila Oliveira. (Re)planejamento de cursos de português como segunda língua: um caminho para política institucional. 2016. 125 f. Dissertação (Mestrado em Linguística Aplicada) - Universidade de Brasília, Brasília, 2016.

PRABHU, Nagore Seshagiri. There is no best method - why? Tesol Quarterly, Washington, v. 24, n. 2, p. 161-176, 1990.

SANTOS, Marcelo; ALMEIDA FILHO, José Carlos Paes de. Análise de abordagem de ensino de língua no limite. Revista SIPLE, Brasília, v. 2, n. 2, p. 102-118, out., 2011.

VIANA, Nelson. O conceito de abordagem na formação e atuação de professores de língua(s): partitura e $(\mathrm{m})$ execução. In: FREITAS, Mirelle da Silva; ORTALE, Fernanda Landucci (org.). Estudos de abordagem no ensino de línguas e formação docente. Campinas: Pontes, 2020. p. 7-14.

YIN, Robert K. Qualitative research from start to finish. 2. ed. New York: The Guilford Press, 2016. 
Submetido em: 31 jul. 2020.

Aceito em: 08 set. 2020. 